Technical note

\title{
Aircraft measurements of BTEX compounds around Beijing city
}

\author{
Kankan Liu ${ }^{\mathrm{a}}$, Jiannong Quan ${ }^{\mathrm{b}, \mathrm{c}}$, Yujing Mu ${ }^{\mathrm{a}, *}$, Qiang Zhang ${ }^{\mathrm{b}, \mathrm{c}}$, Junfeng Liu ${ }^{\mathrm{a}}$, Yang Gao ${ }^{\mathrm{b}, \mathrm{c}}$, \\ Pengfei Chen ${ }^{\mathrm{b}, \mathrm{c}}$, Delong Zhao ${ }^{\mathrm{b}, \mathrm{c}}$, Haijun Tian ${ }^{\mathrm{b}}$ \\ ${ }^{a}$ Research Center for Eco-Environmental Sciences, Chinese Academy of Sciences, Beijing 100085, China \\ ${ }^{\mathrm{b}}$ Beijing Weather Modification Office, Beijing, China \\ ${ }^{\mathrm{c}}$ Beijing Key Laboratory of Cloud, Precipitation and Atmospheric Water Resources, Beijing, China
}

\section{H I G H L I G H T S}

- A high sensitive method for measuring atmospheric BTEX was developed.

- Remarkable decreases of BTEX with increasing height were observed.

- The vertical distribution of $\mathrm{B} / \mathrm{T}$ well revealed air mass aging process.

\section{A R T I C L E I N F O}

Article history:

Received 27 September 2012

Received in revised form

10 January 2013

Accepted 25 February 2013

\section{Keywords:}

BTEX

Aircraft measurement

Cryo-enrichment

GC-PID

\begin{abstract}
A B S T R A C T
A high sensitive method has been developed for measuring atmospheric BTEX (Benzene, Toluene, Ethylbenzene, Xylenes) by using Gas Chromatography equipped with Photo-Ionization Detector (GC-PID). The Method Detection Limits (MDLs) were: Benzene $0.66 \mathrm{ng} \mathrm{m}^{-3}$, Toluene $2.03 \mathrm{ng} \mathrm{m}^{-3}$, Ethylbenzene $5.91 \mathrm{ng} \mathrm{m}^{-3}, \mathrm{~m}, \mathrm{p}$-Xylene $6.49 \mathrm{ng} \mathrm{m}^{-3}$ and o-Xylene $5.45 \mathrm{ng} \mathrm{m}^{-3}$. Vertical distribution of BTEX from ground level to $3600 \mathrm{~m}$ around Beijing city was measured during flight of aircraft in July and November, 2011. Remarkable decrease of each BTEX species with increasing height was observed, and the sum concentration of BTEX decreased from $21.7 \mu \mathrm{g} \mathrm{m}^{-3}$ at ground level to $0.19 \mu \mathrm{g} \mathrm{m}^{-3}$ at height of $3600 \mathrm{~m}$. The ratio of benzene to toluene $(\mathrm{B} / \mathrm{T})$ also increased pronouncedly with increasing altitude, but became flat above $1800 \mathrm{~m}$. The vertical distribution characters of BTEX and B/T were ascribed to diffusion and photochemical consumption of BTEX.
\end{abstract}

(c) 2013 Elsevier Ltd. All rights reserved.

\section{Introduction}

Atmospheric BTEX compounds (Benzene, Toluene, Ethylbenzene and Xylenes) are mainly from various anthropogenic emissions, including fossil fuels' incomplete combustion, industrial production, solvent evaporation etc (Buczynska et al., 2009). They have already aroused concern for their negative healthy impacts on urban residents (Zhang et al., 2012a) and for their influence in atmospheric chemistry (Barletta et al., 2008), and extensive investigations of BTEX have been carried out at ground level (Zhang et al., 2012b) or indoors (Ilgen et al., 2001). A few studies also investigated the vertical distribution of BTEX on high buildings (Jo and Kim, 2002), meteorological tower (Mao et al., 2008), or by balloon (Wőhrnschimmel et al., 2006) with height below $300 \mathrm{~m}$. A number of large-scale aircraft measurements on atmospheric

\footnotetext{
* Corresponding author.

E-mail address: yjmu@rcees.ac.cn (Y. Mu).
}

pollutants have been carried out by some organizations such as TROZ (Fabian and Pruchniewicz, 1977), GASP (Nastrom, 1979), POLLUMET (Lehning et al., 1996), PEACAMPOT (Hatakeyama et al., 1995), Trace-P (Jacob et al., 2003), however, the vertical distribution of BTEX measured by aircraft was rarely reported. To our best knowledge, there are only two reports about the mixing ratios of BTEX above boundary layer (Hopkins et al., 2006; Wang et al., 2009). However, the mixing ratios of BTEX, as mentioned by the authors, couldn't be detected in most samples taken above the boundary layer due to the high detection limits of the GC-FID/MS methods used by the investigations.

Atmospheric BTEX are highly reactive, even though the presence of BTEX in the upper atmosphere is at very low concentration, they may influence the natural photochemical balance, such as formation of extra organic aerosol as well as photo-oxidants. Therefore, measurements of atmospheric BTEX in the upper atmosphere are of great importance.

The objectives of this paper are to set up a high sensitive method for measuring atmospheric BTEX, and to achieve aircraft 
measurements of BTEX in the lower troposphere at different heights.

\section{Materials and methods}

\subsection{Aircraft flight route and sampling}

Aircraft flight route is shown in Fig. 1. The aircraft took off at Shahe airport which locates outside the 6th ring road of Beijing. The airport is only used for training, and there were at most three flights during our sampling days. During vertical sampling, the aircraft spiral down from altitude of $3830 \mathrm{~m}$ with turning radius of about $5000 \mathrm{~m}$ and descend speed of $150 \mathrm{~m} \mathrm{~min}^{-1}$.

Grab sampling was carried out using canisters (3.2 L, Entech Instruments, Inc. US) pre-vacuumed in laboratory. Nine canisters were connected on a bracket which consisted of special copper tubes (Entech Instruments, Inc. US) with inner surface coated with silicon, three-way metric tube fittings (Swagelok) and a three-valve (Swagelok). The canisters were cleaned by repeating evacuation under temperature of $\sim 50{ }^{\circ} \mathrm{C}$ and flushing with purified $\mathrm{N}_{2}$ for three times before shipping to the airplane. The three-valve was manually unclosed when the airplane arrived at a certain height, and then air samples were collected at different heights with opening corresponding valves of the canisters, respectively. The sampling duration for each canister was fixed at 2 min by closing the valve connected with the canister. Air samples at ground level were also collected at the airport before aircraft taking off and on top of a building of Research Center for Eco-Environmental Sciences (RCEES). The detail information of the sampling site of RCEES have been described in our previous publications (Pang and Mu, 2006; Liu et al., 2009). To avoid the possible loss of BTEX via reactions with photo-oxidants during store in the canisters, an oxidantsscrubber $\left(\mathrm{Na}_{2} \mathrm{SO}_{3}\right)$ was placed in front of the air inlet. To avoid dark loss of BTEX in the canisters, all samples were analyzed in the laboratory within two days. The aircraft measurements were conducted seven times in July and five times in November, 2011.

\subsection{Purification of high purity nitrogen}

Because trace impurities of benzene $\left(0.27 \mu \mathrm{g} \mathrm{m}^{-3}\right)$ and toluene $\left(0.12 \mu \mathrm{g} \mathrm{m}^{-3}\right)$ in high purity nitrogen $\left(\mathrm{N}_{2}, 99.999 \%\right)$ from cylinder were found, the $\mathrm{N}_{2}$ was further purified through activated charcoal and Tenax-TA filled in a U-tube soaked in liquid nitrogen (as shown in Fig. 2). No detectable BTEX was found with injection of the purified $\mathrm{N}_{2}$ of $500 \mathrm{~mL}$ enriched on an absorption tube from the canister.

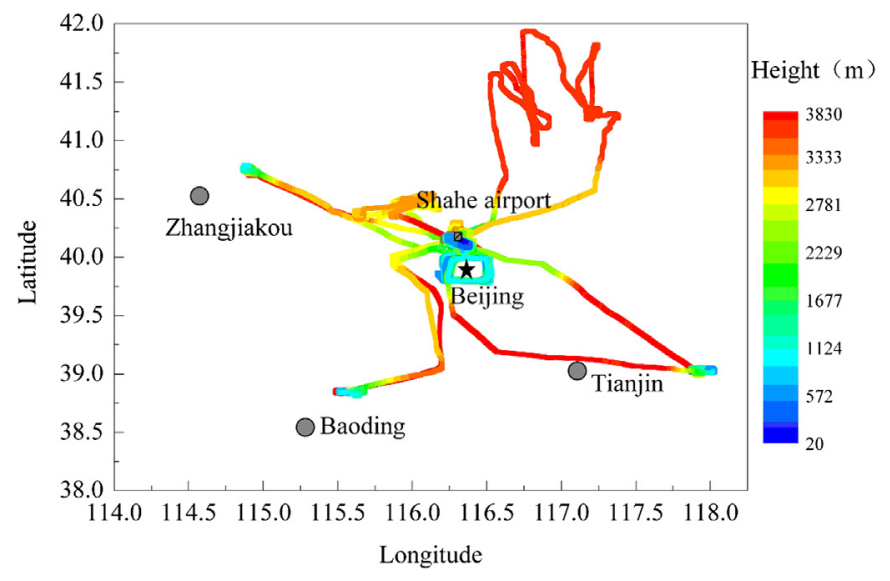

Fig. 1. Aircraft flight route.

\subsection{Standard gas mixture preparation}

The stock standard BTEX mixture in $\mathrm{N}_{2}$ ( $\sim 50$ ppm for each) was purchased from National Research Center for Certified Reference Material. To maintain consistency with the analytical process for air samples, the standard gas mixture was further diluted into different calibration concentrations by the purified $\mathrm{N}_{2}$ in the canisters. The connection tubes and a canister were firstly cleaned via repeating evacuation and flushing for three times and finally evacuated to be less than $-0.65 \mathrm{kPa}$. Then the purified $\mathrm{N}_{2}$ was introduced into the canister at a flow rate of $380 \mathrm{~mL} \mathrm{~min}^{-1}$ via the Flow Restrictor Valve I (Fig. 2, FRV I), and certain amount of the stock standard gas mixture was injected into the canister by a syringe via a septum rubber plugged at the free side of FRV I. According to the difference of the value of pressure gauge between at beginning and finishing calibration gas mixture preparation, the exact volume of gas in the canister under atmospheric pressure and room temperature can be determined in terms of Eq. (1).

$\Delta V=V \cdot \frac{\left(P_{1}-P_{2}\right)}{P_{0}} \times 10^{3}$

where, $\Delta V(\mathrm{~mL})$ is the volume of gas flowed into (or out of) the canister at atmospheric pressure and room temperature, $V(3.2 \mathrm{~L})$ is the volume of the sampling canister, $P_{1}$ and $P_{2}(\mathrm{kPa})$ are the original and final display values of the pressure gauge, $P_{0}(\mathrm{kPa})$ is atmospheric pressure. The concentrations of BTEX compounds in the canister could be easily derived from the injection amount of BTEX and the total amount of gas.

\subsection{Cryo-enrichment}

The air sample collected from the aircraft or the standard gas mixture prepared in the canister was firstly connected with the system of Fig. 2, and the connection lines were pumped with closing the valves of the canister and FRV I, and then the initial pressure in the canister was recorded by closing the valve of FRV II and opening the valve of canister. Secondly, an adsorptive tube (150 mm, I.D. $3 \mathrm{~mm}$ ) filled with Tenax-TA (0.05 g) was connected between the canister and the valve of FRV II with closing the valve of canister and opening the valves of FRV I and FRV II for flushing the tube by the purified $\mathrm{N}_{2}$, and then the absorption tube was put on a Dewar bottle containing liquid nitrogen. Finally, the valve of the canister was slowly opened after closing the valve of FRV I to control sampling flow rate at about $0.2 \mathrm{kPa} \mathrm{s}^{-1}$, equals to $380 \mathrm{~mL} \mathrm{~min}{ }^{-1}$. The total enriched volume for each air sample was about $1 \mathrm{~L}$ (1 atm and room temperature).

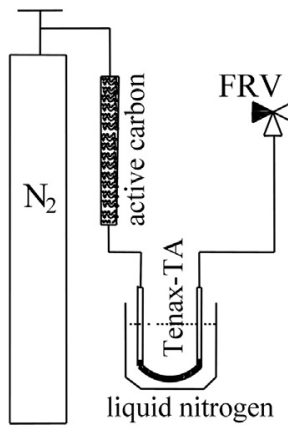

(A) $\mathrm{PN}_{2}$

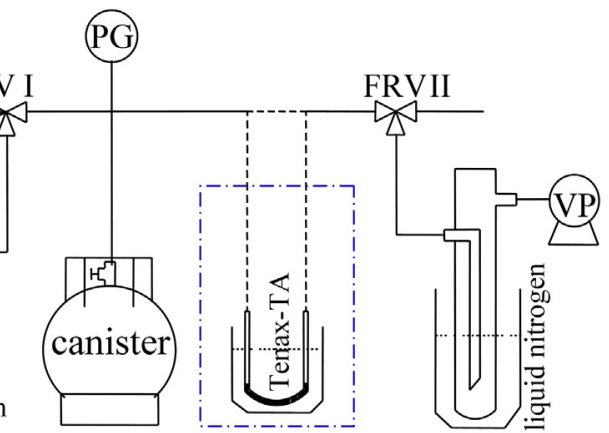

(C) $\mathrm{CE}$

(B) VPS

Fig. 2. The setup of standard gas mixture preparation and Cryo-enrichment: Flow restrictor valves (FRV I and FRV II), Pressure Gauge (PG), Vacuum Pump (VP), Purification of $\mathrm{N}_{2}\left((\mathrm{~A}) \mathrm{PN}_{2}\right)$, Vacuum-Pumping System ((B) VPS), Cryo-enrichment ((C) CE). 


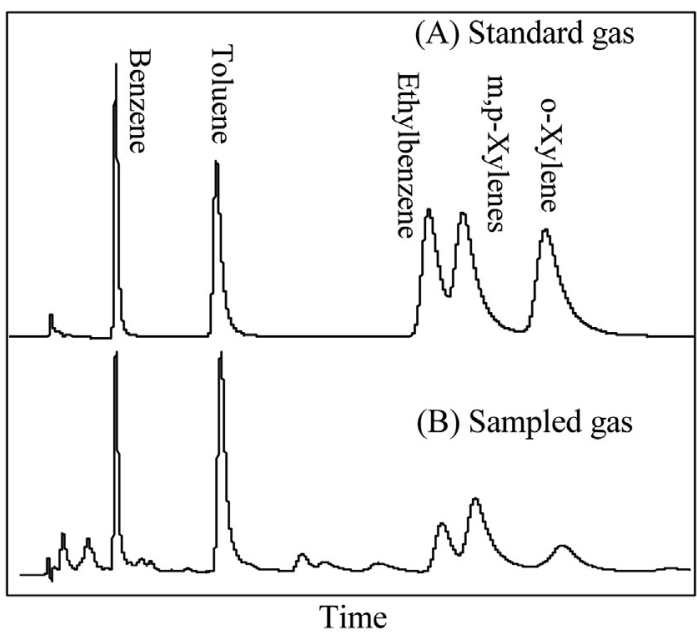

Fig. 3. Gas chromatograms: (A) standard gas mixture, (B) air sample.

\subsection{Analysis and calibration}

The cryo-enriched sample on an adsorptive tube was removed from the system of cryo-enrichment, and connected at once with the six-valve as a loop under flushing with a small flow rate (about $5 \mathrm{~mL} \mathrm{~min}^{-1}$ ) of the purified $\mathrm{N}_{2}$ for about $20 \mathrm{~s}$, then put into a thermal desorption unit with the inlet and outlet closed, and switched the six-valve after heating for $40 \mathrm{~s}$ to inject the sample into the column (SE-30, $20 \mathrm{~m} \times 0.53 \mathrm{~mm} \times 1.0 \mu \mathrm{m})$ for separation. BTEX were detected by GC-PID (GC-4400, East \& West Analytical Instruments Co., Ltd.). The optimized conditions for analyzing were as follows: Desorption stove temperature was $260{ }^{\circ} \mathrm{C}$; the flow rate of carrier gas of $\mathrm{N}_{2}$ for GC-PID was $25 \mathrm{~mL} \mathrm{~min}^{-1}$, and the ratio of injection and split was $1: 5$, the column temperature was $45^{\circ} \mathrm{C}$.

\section{Results and discussion}

\subsection{Separation of BTEX}

Typical gas chromatograms of the standard gas mixture of BTEX and a gas sample collected on aircraft are shown in Fig. 3(A) and (B), respectively. It is evident that the method developed could effectively separate BTEX except for m,p-Xylenes. The signal of each BTEX species in the gas chromatograms of all air samples appeared at corresponding retention time of the standard gas mixture. Because the PID is very sensitive to BTEX, the influence of other compounds with possible co-elution on the column was regarded to be negligible.

\subsection{Reproducibility and detection limit}

To check the reliability of the method developed in this study, the reproducibility was tested for a fixed BETX concentration prepared in one canister for five times and in five canisters as parallel samples, and the results are listed in Table 1 . The relative standard deviation (RSD) for each BTEX species was less than $5 \%$, indicating that the memory effect of the canisters for BTEX was negligible during short time storage and the whole procedure of enrichment and thermal desorption could be well reproduced. In addition, no breakthrough (through test by using two sorbent tubes in series for enrichment) and good linear correlation $(R>0.995)$ between the signal of GC-PID and the amount of BTEX were also verified. Therefore, BTEX in the air samples were quantified by the proportion of their corresponding peak heights and the amount enriched to those of a standard gas mixture freshly prepared on the same

Table 1

Reproducibility of the method (the values are the peak heights of the GC-PID).

\begin{tabular}{|c|c|c|c|c|c|c|c|c|c|c|}
\hline \multirow[t]{2}{*}{$N$} & \multicolumn{5}{|c|}{ One canister } & \multicolumn{5}{|c|}{ Random five canisters } \\
\hline & B & $\mathrm{T}$ & $\mathrm{E}$ & $\mathrm{m}, \mathrm{p}-\mathrm{X}$ & $0-X$ & B & $\mathrm{T}$ & $\mathrm{E}$ & $\mathrm{m}, \mathrm{p}-\mathrm{X}$ & $0-X$ \\
\hline 1 & 139,927 & 52,774 & 21,691 & 15,006 & 17,317 & 138,939 & 52,679 & 20,997 & 14,218 & 16,671 \\
\hline 2 & 144,227 & 50,318 & 22,105 & 13,740 & 16,405 & 138,860 & 53,320 & 20,407 & 13,920 & 17,502 \\
\hline 3 & 141,390 & 50,287 & 21,192 & 14,163 & 15,794 & 143,108 & 52,002 & 21,425 & 14,102 & 17,203 \\
\hline 4 & 139,993 & 50,261 & 19,904 & 13,484 & 15,584 & 139,060 & 52,138 & 21,216 & 13,905 & 17,770 \\
\hline 5 & 138,016 & 51,593 & 20,565 & 14,120 & 15,799 & 137,702 & 52,774 & 22,416 & 14,500 & 16,714 \\
\hline Mean & 140,710 & 51,046 & 21,091 & 14,102 & 16,179 & 139,534 & 52,582 & 21,293 & 14,129 & 17,172 \\
\hline STDEV & 2303 & 1118 & 878 & 577 & 705 & 2071 & 530 & 734 & 245 & 482 \\
\hline RSD/\% & 1.64 & 2.19 & 4.16 & 4.10 & 4.36 & 1.48 & 1.01 & 3.45 & 1.73 & 2.81 \\
\hline
\end{tabular}

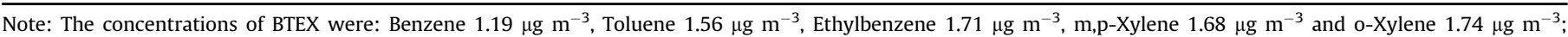
$\Delta V=160 \mathrm{~mL}$.

Table 2

The average concentrations $\left(\mu \mathrm{g} \mathrm{m}^{-3}\right.$ ) of BTEX at each height in July and November.

\begin{tabular}{|c|c|c|c|c|c|c|c|c|c|c|c|c|c|c|c|}
\hline \multirow[t]{2}{*}{ Height/m } & \multicolumn{3}{|c|}{ Benzene } & \multicolumn{3}{|c|}{ Toluene } & \multicolumn{3}{|c|}{ Ethylbenzene } & \multicolumn{3}{|c|}{ m,p-Xylene } & \multicolumn{3}{|c|}{ o-Xylene } \\
\hline & $\mathrm{i}$ & ii & iii & $\mathrm{i}$ & ii & iii & $\mathrm{i}$ & ii & iii & $\mathrm{i}$ & ii & iii & $\mathrm{i}$ & ii & iii \\
\hline RCEES & 2.68 & 3.26 & 4.30 & 5.88 & 7.84 & 9.69 & 1.99 & 1.85 & 2.62 & 3.31 & 2.25 & 3.15 & 1.90 & 2.19 & 1.91 \\
\hline 1 & 1.91 & 2.63 & 3.58 & 2.86 & 4.03 & 6.54 & 1.31 & 1.45 & 4.40 & 1.46 & 1.90 & 3.54 & 1.14 & 1.45 & 2.81 \\
\hline 600 & 0.80 & 0.79 & 1.70 & 0.83 & 1.01 & 1.93 & 0.40 & 0.40 & 1.75 & 0.40 & 0.46 & 1.45 & 0.28 & 0.34 & 0.99 \\
\hline 900 & 0.41 & 0.67 & 1.01 & 0.34 & 0.64 & 0.69 & 0.26 & 0.35 & 0.43 & 0.21 & 0.35 & 0.37 & 0.18 & 0.29 & 0.31 \\
\hline 1500 & 0.31 & 0.43 & 0.76 & 0.24 & 0.31 & 0.39 & 0.16 & 0.21 & 0.30 & 0.13 & 0.17 & 0.28 & 0.11 & 0.14 & 0.25 \\
\hline 1800 & 0.26 & 0.35 & 0.53 & 0.17 & 0.25 & 0.24 & 0.11 & 0.14 & 0.16 & 0.09 & 0.12 & 0.19 & 0.08 & 0.11 & 0.18 \\
\hline 2100 & 0.23 & 0.30 & 0.45 & 0.17 & 0.19 & 0.20 & 0.10 & 0.12 & 0.14 & 0.09 & 0.11 & 0.16 & 0.07 & 0.10 & 0.15 \\
\hline 2400 & 0.17 & 0.23 & 0.35 & 0.11 & 0.14 & 0.15 & 0.07 & 0.09 & 0.11 & 0.06 & 0.08 & 0.11 & 0.06 & 0.08 & 0.12 \\
\hline 2700 & 0.16 & 0.20 & 0.26 & 0.09 & 0.12 & 0.11 & 0.06 & 0.08 & 0.10 & 0.05 & 0.07 & 0.07 & 0.05 & 0.07 & 0.07 \\
\hline 3000 & 0.12 & 0.12 & 0.20 & 0.08 & 0.07 & 0.09 & 0.05 & 0.05 & 0.06 & 0.04 & 0.07 & 0.07 & 0.04 & 0.06 & 0.06 \\
\hline 3600 & 0.08 & 0.12 & 0.15 & 0.04 & 0.07 & 0.06 & 0.03 & 0.05 & 0.10 & 0.03 & 0.07 & - & 0.02 & 0.07 & 0.05 \\
\hline
\end{tabular}

i: July $(n=7)$; ii: November $(n=2)$; iii: November $(n=3)$. 


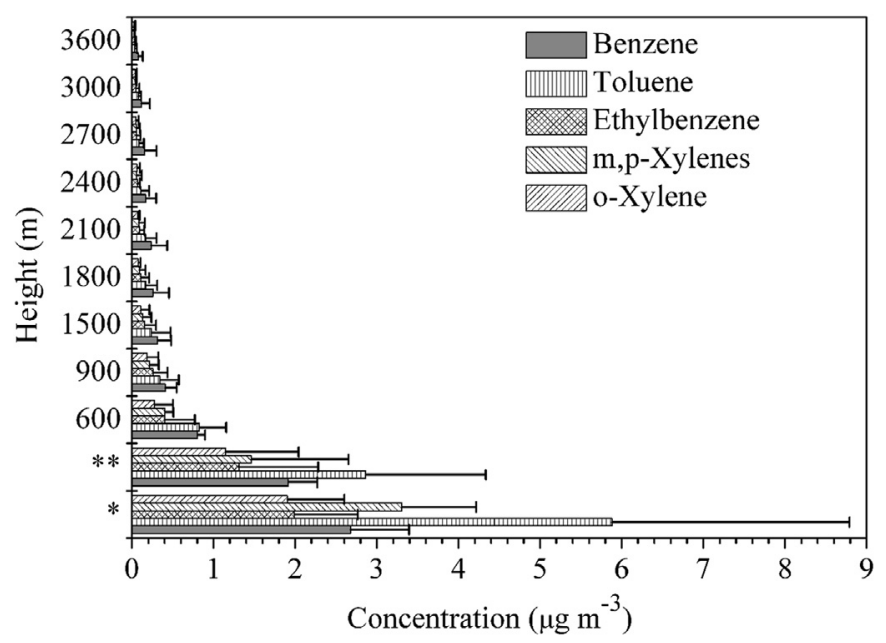

Fig. 4. Vertical distributions of BTEX in July, 2011 ( $^{*}$ and ${ }^{* *}$ represent ground levels collected at RCEES and the airport, respectively).

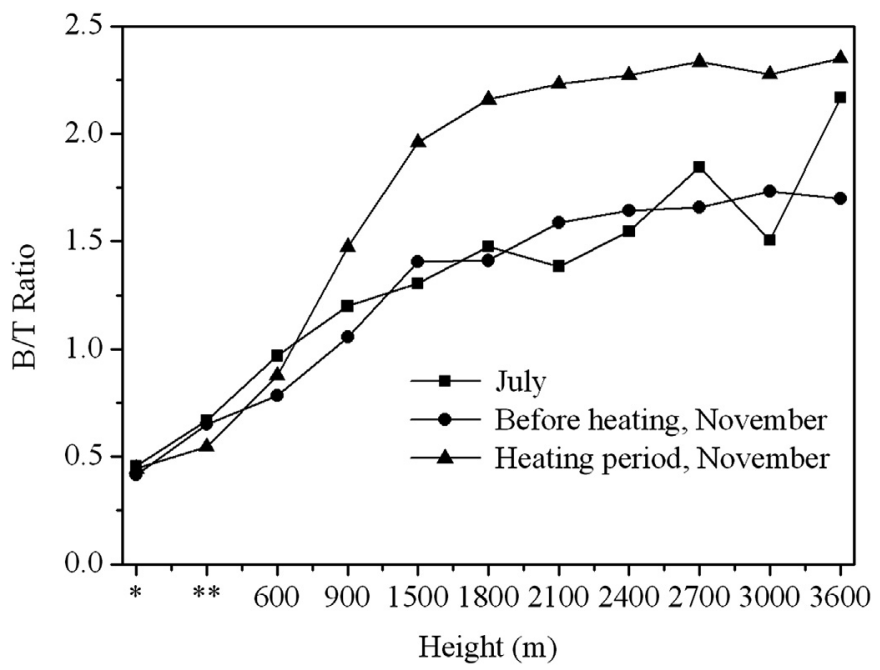

Fig. 5. Vertical distributions of $\mathrm{B} / \mathrm{T}$ ratios in July and November, 2011 ( $^{*}$ and ${ }^{* *}$ represent as Fig. 4). day. The method detection limits (with a signal-to-noise ratio of 3) for benzene, toluene, ethylbenzene, m,p-xylene and o-xylene were $0.66,2.03,5.91,6.49$ and $5.45 \mathrm{ng} \mathrm{m}^{-3}$, respectively.

\subsection{Field measurements}

The average concentrations of BTEX compounds at each height in July and November are listed in Table 2. Because the vertical distributions of BTEX during the two sampling months were similar, only the average vertical distributions in July were illustrated in Fig. 4. It can be seen that the vertical distributions of BTEX displayed an obvious decreasing trend with increasing altitude.

The average concentrations of BTEX at each height in November were about 1.5 times larger than those in July, indicating extra sources (such as heating after 15 November) and low photochemical reactivity in November. The average concentrations of benzene and toluene at height of $2100 \mathrm{~m}$ were $0.33 \mu \mathrm{g} \mathrm{m}^{-3}$ and $0.19 \mu \mathrm{g} \mathrm{m}^{-3}$, respectively, which were about 5 times greater than the values measured by Hopkins et al. (2006) at the same height over the south East of England, but was approximately same as the values $\left(\sim 0.5 \mu \mathrm{g} \mathrm{m}^{-3}\right.$ for benzene and $\sim 0.2 \mu \mathrm{g} \mathrm{m}^{-3}$ for toluene) measured by Wang et al. (2009) over Beijing. In comparison with aircraft measurement over the south East of England, the relatively high concentrations of BTEX around Beijing revealed that the influence anthropogenic emissions in the megacity was not only limited in earth's surface, but also extended to the upper troposphere.

Toluene was the most abundant species among the BTEX at ground, while benzene became the dominant species above $600 \mathrm{~m}$. Because benzene and toluene usually have the common sources but different atmospheric lifetimes, the benzene/toluene ratio $(\mathrm{B} / \mathrm{T})$ is often used as an indicator of the period since an air mass received fresh emissions (Penkett et al., 1993; Mckeen and Liu, 1993). The evident increase of B/T with increasing height, as shown in Fig. 5, well indicated air mass aging process. The pronounced increase below $1800 \mathrm{~m}$ and flat distribution above $1800 \mathrm{~m}$ for B/T were coincident with the decrease trends of BTEX. Because the boundary layer around Beijing is usually less than $1800 \mathrm{~m}$ (Wang et al., 2008), the vertical distributions of BTEX and $\mathrm{B} / \mathrm{T}$ were suspected to relate with the boundary. The diffusion rates of atmospheric pollutants within the boundary might be greatly restrained, and thus their

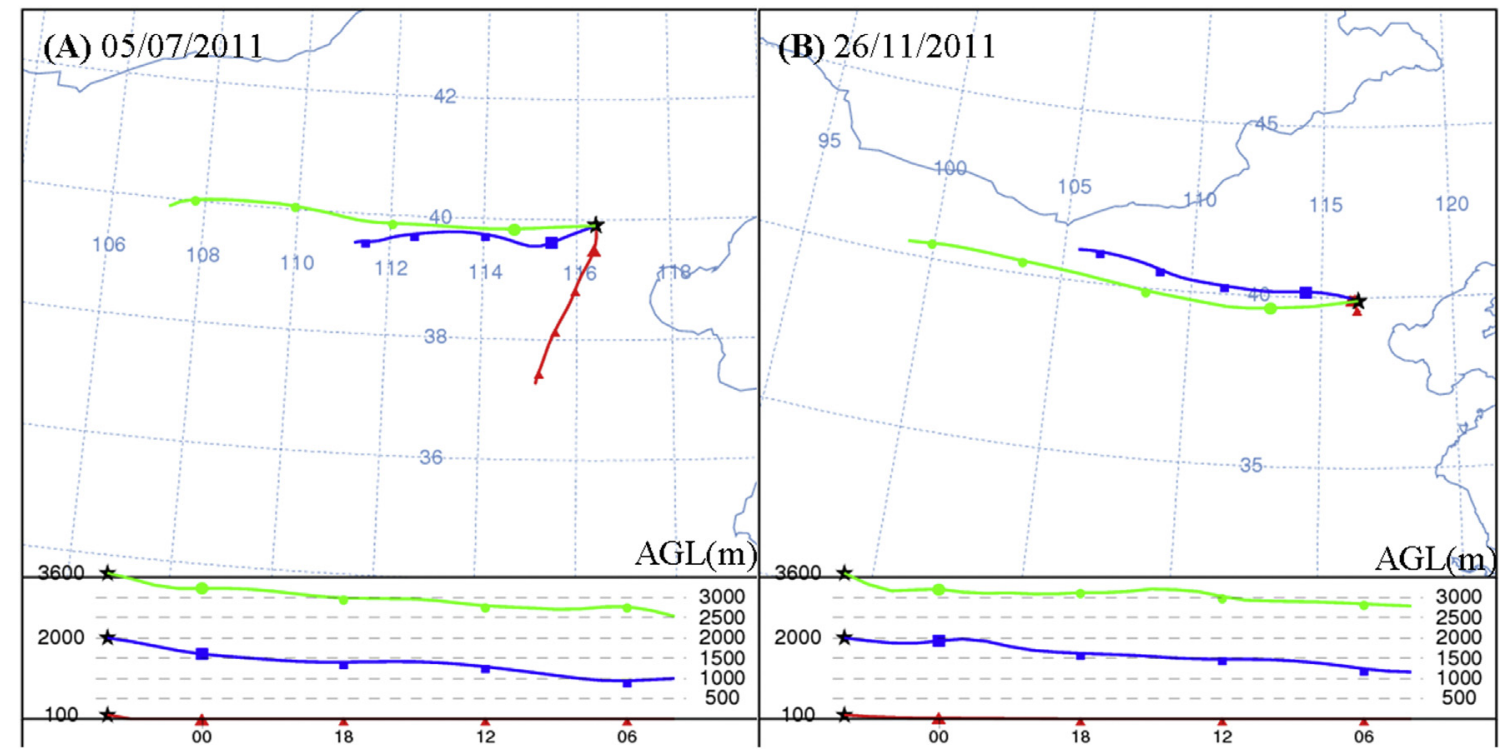

Fig. 6. The $24 \mathrm{~h}$ backward trajectories of air mass at three heights on 5th July and 26th November, 2011. 
diffusion from lower to higher altitude would take longer time, resulting in the pronounced distribution of BTEX and B/T. As BTEX diffuse above the boundary layer, their faster diffusions would result in relatively even vertical distributions for them. It is interesting to note that the vertical distributions of the average $\mathrm{B} / \mathrm{T}$ ratios in July and before heating were almost identical, but significantly lower than that during heating period at heights above $900 \mathrm{~m}$. In order to explain the reason, the origins of air mass at three heights were analyzed by back trajectories. Because the aircraft sampling days were mainly selected under stable weather condition, all results revealed that the origins of air mass were mainly dominated by horizontal transportation, and only the back trajectories on 5th July and 26th November are illustrated in Fig. 6. It is evident that only the origins of air mass couldn't account for the relative high ratio of $\mathrm{B} / \mathrm{T}$ above $900 \mathrm{~m}$ during heating period. Because coal combustion with relatively high $\mathrm{B} / \mathrm{T}$ ratio is widely used for heating by farmers in China, the evident difference of $\mathrm{B} / \mathrm{T}$ ratios above $900 \mathrm{~m}$ was ascribed to the upwards diffusion of polluted air from villages around Beijing. Although coal combustion for heating in Beijing has been replaced by relatively clean fuel energy (such as oil and natural gas), extremely high ratios (around 1) of $B / T$ in the afternoon during heating period were frequently observed in our previous studies (Zhang et al., 2012a). The almost identical $\mathrm{B} / \mathrm{T}$ ratios at ground during the sampling periods in this study were probably due to fewer samples during the heating period and the sampling time conducted in the morning when the air pollutants were dominated by local emission from vehicle exhaust. The $\mathrm{B} / \mathrm{T}$ ratios at height of $2100 \mathrm{~m}$ were in the range of $1.3-$ 2.3, which were much lower than 13.35 reported by Hopkins et al. (2006) at the same height, but were close to the value $(\sim 2.5)$ reported by Wang et al. (2009).

\section{Conclusions}

The method developed in this study was demonstrated to completely meet the requirements for aircraft measurements of BTEX. The distinct vertical distributions of BTEX and B/T ratios over Beijing well reflected air mass aging process. The relatively high concentrations of BTEX in the upper atmosphere around Beijing city implied that the anthropogenic emissions are influencing on the natural photochemical balance, such as, formation of extra organic aerosol as well as photo-oxidants in the upper atmosphere.

\section{Acknowledgments}

This work was financially supported by the Chinese National Natural Science Foundation (41175007, 41075094, 21177140, 40905060 , and 40830101), the project of scientific and technological new star of Beijing (2010B029) and the National Basic Research and the Development Program 973 (2011CB403401, 2010CB732304).

\section{References}

Barletta, B., Meinardi, S., Simpson, I.J., Zou, S., Rowland, F.S., 2008. Ambient mixing ratios of nonmethane hydrocarbons (NMHCs) in two major urban centers of the Pearl River Delta (PRD) region: Guangzhou and Dongguan. Atmospheric Environment 42, 4393-4408.

Buczynska, A.J., Krata, A., Stranger, M., Godoi, A.F.L., Kontozova-Deutsch, V., Bencs, L., Naveau, I., Roekens, E., Grieken, R.V., 2009. Atmospheric BTEXconcentrations in an area with intensive street traffic. Atmospheric Environment 43, 31-318.

Fabian, P., Pruchniewicz, P.G., 1977. Meridional distribution of ozone in the troposphere and its seasonal variations. Journal of Geophysical Research 82 (15), 2063-2073.

Hatakeyama, S., Murano, K., Bandow, H., Sakamaki, F., Yamato, M., Tanaka, S. Akimoto, H., 1995. The 1991 PEACAMPOT aircraft observation of ozone, $\mathrm{NO}_{\mathrm{x}}$ and $\mathrm{SO}_{2}$ over the East China Sea, the Yellow Sea, and the Sea of Japan. Journal of Geophysical Research 100 (D11), 23143-23151.

Hopkins, J.R., Boddy, R.K., Hamilton, J.F., Lee, J.D., Lewis, A.C., Purvis, R.M., Watson, N.J., 2006. An observational case study of zone and precursors inflow to South East England during an anticyclone. Journal of Environment Monitoring 8, 1195-1202.

Ilgen, E., Karfish, N., Levsen, K., Angerer, J., Schneider, P., Heinrich, J. Wichmann, H.E., Dunemann, L., Begerow, J., 2001. Aromatic hydrocarbons in the atmospheric environment. Part I. Indoor versus outdoor sources, the influence of traffic. Atmospheric Environment 35, 1235-1252.

Jacob, D.J., Crawford, J.H., Kleb, M.M., Connors, V.S., Bendura, R.J., Raper, J.L., Sachse, G.W., Gille, J.C., Emmons, L., Heald, C.L., 2003. The transport and chemical evolution over the Pacific (Trace-P) aircraft mission: design, execution and first results. Journal of Geophysical Research 108 (D20), 9000.

Jo, W.K., Kim, K.Y., 2002. Vertical variability of volatile organic compound (VOC) levels in ambient air of high-rise apartment buildings with and without occurrence of surface inversion. Atmospheric Environment 36, 5645-5652.

Lehning, M., Richner, H., Kok, G.L., 1996. Pollutant transport over complex terrain: flux and budget calculations for the POLLUMET field campaign. Atmospheric Environment 30 (18), 3027-3044.

Liu, J.F., Mu, Y.J., Zhang, Y.J., Zhang, Z.M., Wang, X.K., Liu, Y.J., Sun, Z.Q., 2009. Atmospheric levels of BTEX compounds during the 2008 Olympic Games in the urban area of Beijing. Science of the Total Environment 408, 109-116.

Mao, T., Wang, Y.S., Jiang, J., Wu, F.K., Wang, M.X., 2008. The vertical distributions of VOCs in the atmosphere of Beijing in autumn. Science of the Total Environment 390, 97-108.

Mckeen, S.A., Liu, S.C., 1993. Hydrocarbon ratios and photochemical history of air masses. Geophysical Research Letters 20 (21), 2363-2366.

Nastrom, G.D., 1979. Ozone in the upper troposphere from GASP measurements. Journal of Geophysical Research 84 (C7), 3683-3688.

Pang, X.B., Mu, Y.J., 2006. Seasonal and diurnal variations of carbonyl compounds in Beijing ambient air. Atmospheric Environment 40, 6313-6320.

Penkett, S.A., Blake, N.J., Lightman, P., Marsh, A.R.W., Anwyl, P., Butcher, G., 1993. The seasonal variation of nonmethane hydrocarbons in the free troposphere over the North Atlantic Ocean: possible evidence for extensive reaction of hydrocarbons with the nitrate radical. Journal of Geophysical Research 98 (D2), 2865-2885.

Wang, S.Y., Shao, M., Wang, W., 2009. The measurement of vertical distribution of airborne VOCs mixing ratios in Beijing. China Environmental Science 29 (7), 679-684 (in Chinese)

Wang, Z.Z., Li, J., Zhong, Z.Q., Liu, D., Zhou, J., 2008. LIDAR exploration of atmospheric boundary layer over downtown of Beijing in summer. Journal of Applied Optic 29 (1), 96-100.

Wőhrnschimmel, H., Márquez, C., Mugica, V., Staheld, W.A., Staehelinb, J., Cárdenasa, B., Blanco, S., 2006. Vertical profiles and receptor modeling of volatile organic compounds over Southeastern Mexico City. Atmospheric Environment 40, 5125-5136.

Zhang, Y.J., Mu, Y.J., Liu, J.F., Mellouki, A., 2012a. Levels, sources and health risks of carbonyls and BTEX in the ambient air of Beijing, China. Journal of Environmental Sciences 24 (1), 124-130.

Zhang, Y.J., Mu, Y.J., Liang, P., Xu, Z., Liu, J.F., Zhang, H.X., Wang, X.K., Gao, J., Wang, S.L., Chai, F.H., Mellouki, A., 2012b. Atmospheric BTEX and carbonyls during summer seasons of 2008-2010 in Beijing. Atmospheric Environment 59, 186-191. 